\section{Differential Response of Some Tomato Genes to Base-specific Mutagens}

A NUMBer of chemicals are now known which affect specific bases of the DNA molecule ${ }^{1}$. These include the base analogues (such as fluorodeoxyuridine) and others like hydroxylamine and hydrazine which react mainly with cytosine and thymine respectively under particular conditions of treatment. The action of many of these chemicals on chromosomes and genes in higher organisms has not been tested extensively, but some reports are available which show that they induce localized damage in the nucleus ${ }^{2-4}$. We have observed a differential reaction of tomato chromosomes when pollen mother cells are treated with hydroxylamine ${ }^{5}$. The main finding was that a few of the chromosomes, particularly chromosome 2 , were much less damaged than other members of the complement. These experiments with hydroxylamine and a number of other chemicals and X-rays have now been extended to compare the spectrum of mutations induced by them; the present communication relates to some of the results obtained.

The different treatments, details of which are presented in Table 1, were given to seeds (500 in each case) presoaked in water for various durations. The $p \mathrm{H}$ 's of the freshly-prepared solutions were adjusted in a manner described elsewhere ${ }^{5}$. The observations on induced mutations were recorded mainly on seedlings which are easier to handle in large numbers. Also, a number of gene mutations affecting seedling characters are known to give such characteristic phenotypes that the induced variation can easily be scored for them ${ }^{6}$.

These observations make it clear that hydrazine and hydroxylamine induce mutations at a number of loci with very different frequencies. These loci, moreover, are not randomly distributed in the genome. A number of them $(d, a w, w o)$ are known to be located on one particular chromosome (chromosome 2). It should be emphasized that although hydroxylamine failed to induce mutations at these loci, the overall mutation rate with this chemical was higher than that with hydrazine, as shown by the frequency of lethal seedlings and other variation not included here because it could not easily be classified in relation to any of the known genes. Also, for comparable concentrations, hydroxylamine is found to induce sig. nificantly greater chromosomal damage and reduce germination percentage to a much greater extent (see Table 1). Ethylmethanesulphonate, which is known to react with several bases? differs from both in inducing chlorophyll deficiencies of various kinds, but apart from this, it appears to correspond in its action more to hydroxylamine than to hydrazine.
The observations, and the cytological analysis reported earlier, suggest that a number of loci, particularly on chromosome 2 , may be characterized by an inhomogeneity in the distribution of adenine-thymine and guaninecytosine base pairs in their DNA. Differences in base composition of this nature, if confirmed, may prove to be of considerable interest, for they may be of significance in relation to what $\mathrm{Rick}^{8}$ has described as the asymmetrical distribution of genes on tomato chromosomes, with chromosome 2 having nearly 25 per cent of all the mapped genes located on it. No satisfactory explanation for this asymmetry has so far been available. Further analysis using techniques based on autoradiography and ultracentrifugation is in progress.

We thank Dr. M. S. Swaminathan for his kind interest ir this work.

H. K. JAIN

R. N. RAUT

Botany Division,

Indian Agricultural Research Institute, New Delhi.

${ }^{1}$ Freesc, F., Molecular Genetics, Part I, 207, edit. by Taylor (Academic Press, New York, 1963).

${ }^{2}$ Somers, E. C., and Hsu, T. C., Proc. U.S. Nat. Acad. Sci., 4-8, 937 (1962).

3 Natarajan, A. T., and Upadhya, M. D., Chromosoma, 15, 156 (1964).

4 McLeish, J., Heredity, 8, 385 (1954).

${ }^{5}$ Jain, H. K., and Raut, R. N., Experientia, 21, 322 (1965).

- Rick, C. M., and Butler, L., Adv. Genet., 8, 267 (1956).

2 Kreig, D. R., Genetics, 48, 561 (1963).

8 Rick, C. M., Proc. U.S. Nat. Acad, Sci., 45, 1515 (1959).

\section{CYTOLOGY}

\section{Cytoplasmic Deoxyribonucleic Acid-containing Bodies in Amoebae}

EvIDENCE has been presented, from investigations involving techniques of nuclear transfer and injections of cytoplasm, that certain cellular properties of Amoeba proteus and Amoeba discoides, such as nuclear diameter and sensitivity to streptomycin, are influenced by selfreplicating cytoplasmic hereditary determinants ${ }^{1-6}$. The finding of DNA- and RNA-containing bodies in the cytoplasm of Amoeba proteus ${ }^{7-9}$, followed by the demonstration that these bodies are self-replicating within the cell ${ }^{8,8}$ and that they show a certain degree of interaction with the nucleus of amoeba ${ }^{8}$, has stimulated interest in the possibility that they contain the physical basis of this cytoplasmic inheritance ${ }^{6}$.

Cells of the strain of Amoeba proteus, ${ }_{\mathrm{T} l} P$, and the strain of $A$ moeba discoides, $\mathrm{T} l D$, used in the nuclear transfer

Table 1

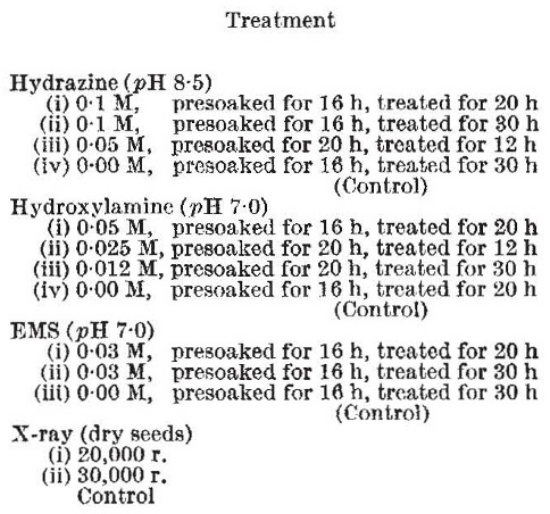

Frequency of different mutant seedlings

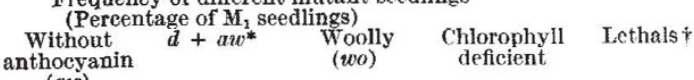
(aw) (per cent)

\title{
(d)
}

$$
0.98
$$$$
0 . \overline{95}
$$$$
\begin{aligned}
& 0.49 \\
& 1.00 \\
& 0.63
\end{aligned}
$$$$
\begin{aligned}
& 0.50 \\
& 0.95
\end{aligned}
$$$$
0.95
$$$$
0.98
$$$$
\begin{aligned}
& 0.98 \\
& 0.50 \\
& 0.63
\end{aligned}
$$$$
0.63
$$$$
-
$$$$
\begin{array}{r}
0.98 \\
1 \cdot 50
\end{array}
$$$$
\begin{array}{r}
63 \cdot 0 \\
64 \cdot 8
\end{array}
$$$$
\begin{aligned}
& 17 \cdot 4 \\
& 46 \cdot 4
\end{aligned}
$$$$
\begin{aligned}
& 46 \cdot 4 \\
& 45 \cdot 9 \\
& 76 \cdot 6
\end{aligned}
$$$$
\text { - - }
$$$$
\overline{-}
$$$$
=
$$$$
\text { - }
$$$$
\text { - }
$$$$
-
$$$$
\text { - }
$$

$\begin{array}{rrrrrrr}47.6 & - & - & - & 0.42 & 1.84 & 7.92 \\ 45.4 & 0.44 & - & - & - & - & - \\ 80.8 & - & - & & & & \\ 64.2 & - & - & - & - & - & 0.21 \\ 53.8 & - & - & - & 0.28 & - & 0.82\end{array}$

Sce Rick and Butler (ref. 6) for a description of the

* The simultaneous induction of these double mutants of linked genes is obviously of considerable significance.

* The simultaneous induetion of these double mutants of linked genes is obviously of considerable significance. hydrazine induce them with significantly different ( 1 per cent level) frequencies. 